\title{
Study on forming process and spring back control of high strength sheet based on Dynaform
}

\author{
Liu cunping ${ }^{1, \mathrm{a}}$ \\ ${ }^{1}$ Yibin Vocational and Technical College, Department of Modern manufacturing, 644003 Sichuan Province, China
}

\begin{abstract}
The drawing process of a high strength steel part without blank holder force was numerically simulated based on Dynaform. In present investigation, the drawing velocity and velocity profile motion of punch was studied by simulating the drawing operation of high strength steel part. The results show that restricting drawing velocity and controlling velocity profile motion of punch could all reduce the spring back. The measure of restricting drawing velocity could reduce non-pressure forming spring back about $31 \%$ and Trapezoidal motion mode of punch is the most beneficial to reduce spring back.
\end{abstract}

\section{Introduction}

In recent yeas, large consumption of natural resources and energy have caused serious pollution for the environment. With the development of technology for energy saving, lightweight technology emerges as the times require. The investigation showed that vehicle weight reduced by $1 \%$, and the fuel required will be reduced by $0.6 \%-1.0 \%$ [1]. To some extent, the lightweight of automobile technology represents the level of modern automobile technology. Lightweight of automobile is to reduce the weight of automobile. The most important method is the use of high strength and lightweight steel plate. According to related literature [26], high strength steel sheet as the automobile material has the advantages both in manufacturing cost and service performance. So, the application of high strength steel is booming and the use of high strength steel in automobile becomes the main trend in automobile manufacture field.

Although high strength steel has advantage of strength and light weight, formability is relatively worse than common plate, especially in aspect of spring back[7,8,9]. And, spring back is the main quality problem in the forming process of high strength steel. It may impact he forming precision of the work piece and the subsequent assembly quality. Therefore, it has very important significance to study the spring back in the stamping forming process of high strength plate. Much research has been done on investigating the spring back for achieving the precision part via the finite element method[10-21].

This paper studies the spring back phenomenon based on simulation. The factors of drawing velocity and velocity profile motion of punch were investigated. Based on results, we could know the deformation rule of this part and improved the technology method. We not only improved the precision and quality of the work piece, but reduced the production cost.

\section{Material and experimentation}

\subsection{Material}

Material used in this study was B340LA sheet of $1.8 \mathrm{~mm}$ thickness, which is a low alloy high strength steel plate for automobile produced by Baosteel. The main property parameters of B340LA sheet metal plate were listed in Table 1.

Table 1. Mechanical properties of B340L
\begin{tabular}{|c|c|}
\hline Condition & Parameters \\
\hline $\begin{array}{c}\text { Tensile } \\
\text { strength(MPa) }\end{array}$ & 490 \\
\hline $\begin{array}{c}\text { Yield } \\
\text { strength(MPa) }\end{array}$ & 380 \\
\hline Elongation(\%) & 0.22 \\
\hline $\begin{array}{c}\text { Poisson's ratio } \\
\text { Anisotropy } \\
\text { parameter }\end{array}$ & 0.28 \\
\hline $\begin{array}{c}\text { Strain } \\
\text { hardening } \\
\text { exponent(MPa) }\end{array}$ & 712.4 \\
\hline
\end{tabular}

\subsection{CAD and FE model}

Three dimensional model building with UG software is shown in Figure 1. It is a complex high strength plate forming part with irregular shape. The right side of the center line has a certain radian relative to the left side. The data built in UG software was converted to IGS format and saved. Then, the IGS data was imported into Dynaform software, which was a commercially available

\footnotetext{
a Corresponding author: liucunping@126.com
} 
Dynaform software version 8.9.1 and it was a nonlinear dynamic simulation package which could simulate different types of sheet metal processes like drawing, bending, stamping, etc. to predict thickness distribution, strains, stresses, etc. Using surface mesh tool in the preprocessor, the part was meshed with an element size of $5 \mathrm{~mm}$. After the meshing, the quality of the mesh was checked and modified. The final finite element model is shown in Figure 2.

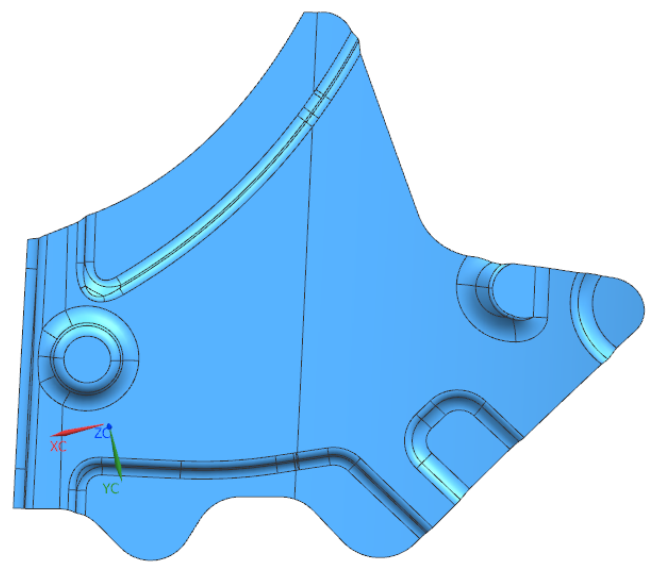

Figure 1. The Model of 3D part.

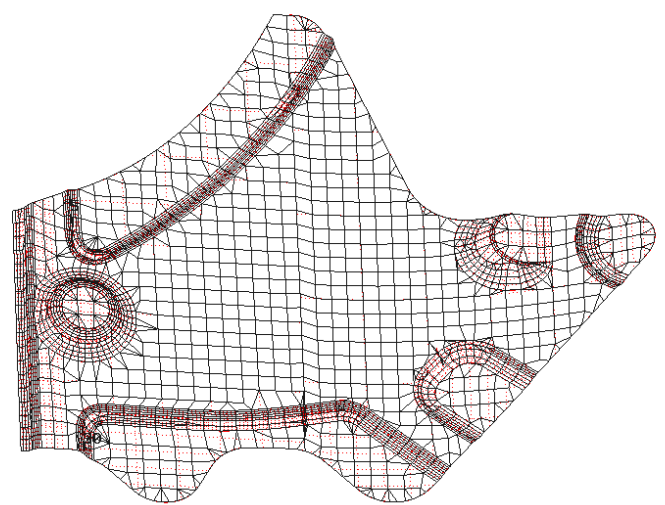

Figure 2. Finite element model for simulation.

\subsection{Design of addendum surface}

According to the characteristics of part, the binder surface and draw bead were not designed during the forming. In order to make qualified parts, the addendum surface was added on the original part and sheared after the process forming. The addendum surface is refers to blending surface between the edge extension of part and binder surface. Smoothing as much as possible is the key for design of addendum surface. This design is more beneficial to material flow.

Using Die Face Engineering (DFE) tool in the preprocessor, addendum surface shape had been made. Figure 3 shows the geometry of the addendum surface used in FE simulations.

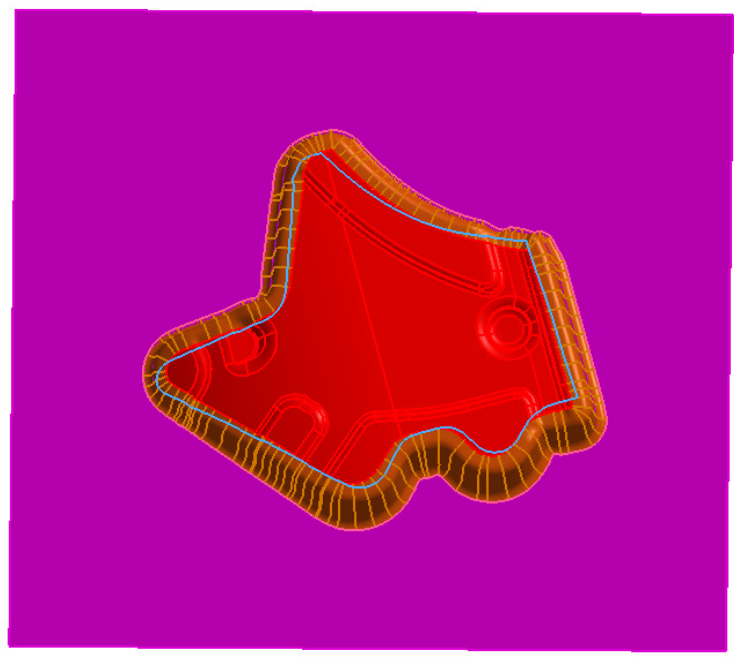

Figure 3. Finite element model after creating the addendum surface for part.

\section{Simulation work}

By ways of changing the size of the blank, modifying the geometrical parameters, and other means to reduce the influence of wrinkles and fracture in sheet metal forming process, forming quality of work piece was significantly improved. Figure 4 shows the final forming limit drawing of high strength steel part. By optimizing the operation, selecting the appropriate parameters which are important effect for forming process can effectively improve the work piece quality. A small part of wrinkling still exists on edge of work piece (purple region), probably because the sheet metal flow is too rapid at the inclined surface. Because wrinkling region is small and no fracture, the work piece is up to standard.

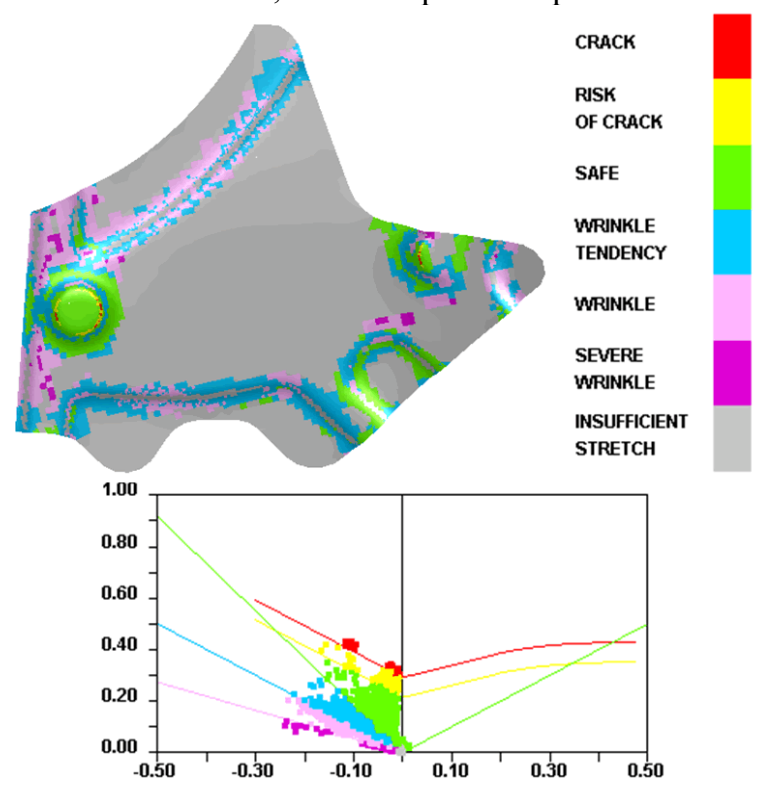

Figure 4. The final forming limit drawing of high strength sheet without blank holder.

\section{Results and discussion}

\subsection{Effect of drawing velocity}


To clearly understand the effects of the drawing velocity on the spring back characteristics in the case of without blank holder force, the drawing velocity levels of $300 \mathrm{~mm} / \mathrm{s}, 500 \mathrm{~mm} / \mathrm{s}, 800 \mathrm{~mm} / \mathrm{s}, 1000 \mathrm{~mm} / \mathrm{s}, 2000 \mathrm{~mm} / \mathrm{s}$, $4000 \mathrm{~mm} / \mathrm{s}, 6000 \mathrm{~mm} / \mathrm{s}, 8000 \mathrm{~mm} / \mathrm{s}$ were investigated. Figure 5 shows the comparison between model dimension and the retention dimension after spring back for different drawing velocity. From the graphs it is observed that the impact of drawing velocity on the spring back has an optimum value, as the drawing velocity increases before the point velocity, the spring back decreases initially. When the velocity is greater than the point velocity, the spring back decreases slowly. Spring back can be related to the drawing velocity. Figure 6 shows the measuring position of spring back.

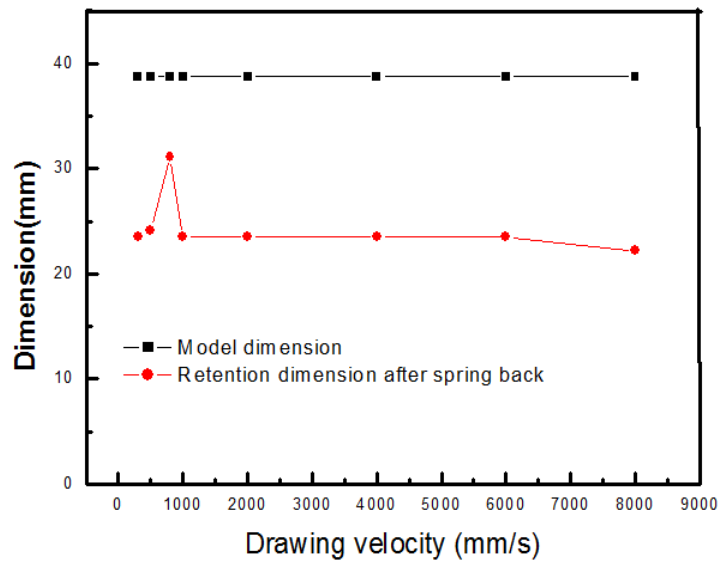

Figure 5. The relationship between drawing velocity and spring back.

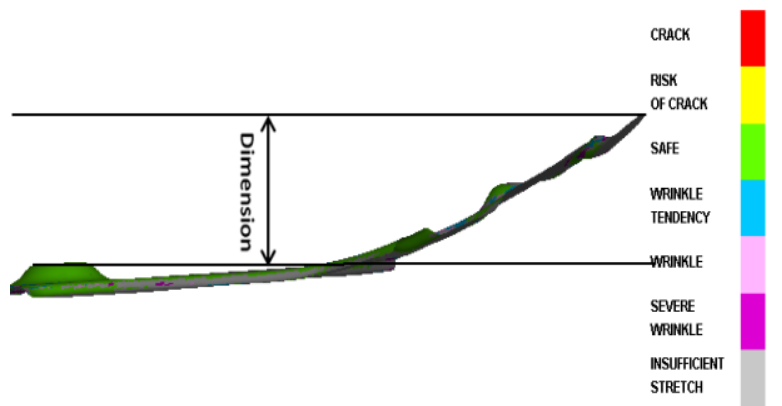

Figure 6. Measuring position of spring back.

\subsection{Effect of velocity profile of the punch}

It has been found experimentally that punch movement trajectory has effect on the spring back. To clearly understand the effects of the velocity profile of the punch on the spring back characteristics, the velocity profile of the punch, which is the Trapezoidal profile (TLP) motion, Triangular profile (TRP) motion and Sinusoidal profile (SP) motion, were investigated. In this simulation, the punch and the die was fixed while the punch was moved with a velocity of $1000 \mathrm{~mm} / \mathrm{s}$ in negative $\mathrm{Z}$ direction. The punch motion was defined using these three profile, as shown in Figure 7.

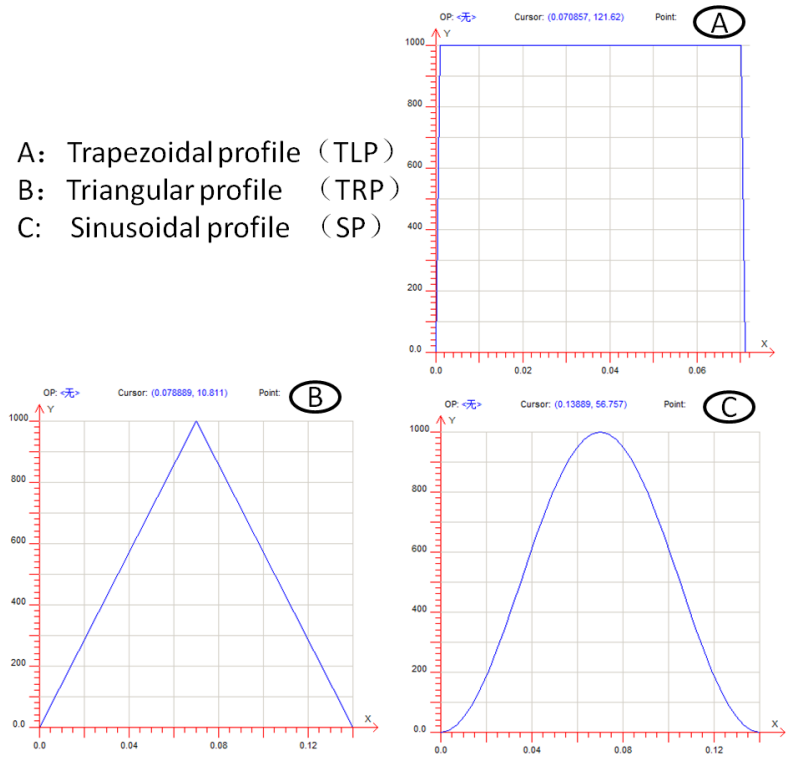

Figure 7. Three different velocity profiles of the punch

Table 2 shows the model predicted dimension spring back with deferent velocity profiles. The maximum retention spring back was found to be $23.55 \mathrm{~mm}$, when the punch velocity profile is Trapezoidal profile motion. To some extent, the punch velocity profile could reduce the spring back.

Table 2. Effect of deferent velocity profiles of the punch for

\begin{tabular}{|c|c|}
\hline $\begin{array}{c}\text { Movement } \\
\text { form }\end{array}$ & $\begin{array}{c}\text { Retention } \\
\text { Value of Spring } \\
\text { back(mm) }\end{array}$ \\
\hline TLP & 23.55 \\
\hline TRP & 22.97 \\
\hline SP & 22.82 \\
\hline
\end{tabular}

\section{Conclusion}

In this study, drawing velocity and velocity profile of punch on the spring back characteristics in the forming process were investigated using finite element method simulations. This study process was having large potential to be used in industries and this method could be extended to different types components. In this forming process, the following conclusions had been obtained:

- In the process of high strength plate forming by ways of changing the size of the blank, modifying the geometrical parameters, and other methods, the forming limit diagram and spring back distribution of the work piece were obtained and these consequences had instruction for practical production.

- The research of drawing velocity showed that the spring back of work piece reaches a minimum value at the velocity about $800 \mathrm{~mm} / \mathrm{s}$, then decreased up to a relative stable value with the increase of velocity.

- The punch movement trajectory had effect on the spring back. Compared with the other two profile motion, 
the trapezoidal profile motion of punch was the most beneficial to reduce spring back.

\section{References}

1. KANG Yong-lin, Iron and Steel 43, 1(2008)

2. Y. Zhang, X. Lai, P. Zhu, W. Wang, MATER DESIGN 27, 64(2006)

3. X. Cui, H. Zhang, S. Wang, L. Zhang, J. Ko, MATER DESIGN 32, 815(2011)

4. M. Kiani, I. Gandikota, M. R. Rohani, K. Motoyama, Journal of Magnesium and Alloys 2, 99(2014)

5. W. Sun, X. Chen, L. Wang, Energy Procedia 88, 889(2016)

6. R.A. Witik, J. Payet, V. Michaud, C. Ludwig, J.E. Manson, COMPOS PART A-APPL S 42, 1694(2011)

7. S.H. Choi, K.G. Chin, J MATER PROCESS TECH 171, 385(2006)

8. F Ozturk, S Toros, S Kilic, J IRON STEEL RES INT 16, 41(2009)

9. C. Gomes, O. Onipede, M. Lovell, J MATER PROCESS TECH 159, 91(2005)

10. M. Samuel, J MATER PROCESS TECH 105, 382(2000)

11. T. Meinders, I.A. Burchitz, M.H.A. Bonte, R.A. Lingbeek, INT J MACH TOOL MANU 48, 499(2008)

12. M. Bakhshi-Jooybari, B. Rahmani, V. Daeezadeh, A. Gorji, MATER DESIGN 30, 2410(2009)

13. S. Chatti, N. Hermi, COMPUT STRUCT 89, 1367(2011)

14. D. Zhang, Z. Cui, X. Ruan, Y. Li, COMP MATER SCI 38, 707 (2007)

15. M.A. Guler, F. Ozer, M. Yenice, M. Kaya, Steel Res Int 81,801 (2010)

16. S. Thipprakmas, U. Boochakul, Int J Precis Eng Manuf 16,1441 (2015)

17. D.K. Leu, Int J Adv Manuf Technol 79, 1095(2015)

18. J. Lee, K. Lee, D. Kim, H. Choi, B. Kim, COMP MATER SCI 100, 76(2015)

19. P. Chen, M. Koc, J MATER PROCESS TECH 190, 189(2007)

20. M. Firat, COMP MATER SCI 43, 802(2008)

21. H.L. Dai, H.J. Jiang, T. Dai, W.L. Xu, A.H. Luo, J ALLOY COMPD 708, 575(2017) 